\title{
DIETAS À BASE DE MILHO E FARELO DE SOJA SUPLEMENTADAS COM ENZIMAS NA ALIMENTAÇÃO DE FRANGOS DE CORTE
}

\author{
DELMA MARIA TORRES ${ }^{1}$ \\ JUDAS TADEU DE BARROS COTTA ${ }^{2}$ \\ ANTONIO SOARES TEIXEIRA ${ }^{2}$ \\ JOEL AUGUSTO MUNIZ ${ }^{3}$ \\ RICARDO ALVES DA FONSECA ${ }^{4}$ \\ EDER CLEMENTINO DOS SANTOS ${ }^{5}$ \\ EDUARDO LUIS ALVES
}

\begin{abstract}
RESUMO - Com o objetivo de verificar o efeito da adição de enzimas digestivas exógenas em dietas à base de milho e farelo de soja sobre o desempenho de frangos de corte, conduziu-se este experimento. Foram utilizados 819 pintos Hubbard em DIC e esquema fatorial $3 \times 2 \times 2+1$ (enzimas, proteínas, níveis de energia e um tratamento testemunha) com 3 repetições de 21 aves por parcela. Os níveis de enzimas foram 0,$5 ; 1,0$ e $1,5 \mathrm{~g} / \mathrm{kg}$ de dieta, e os de proteína foram normais $(21,18,19,95 \mathrm{e}$ $19,43 \%$ PB) e reduzidos $(20,54,19,35$ e $18,46 \%$ PB); os de energia também foram normais $(3000,3100$ e 3200 $\mathrm{kcal} / \mathrm{kg}$ de EM) e reduzidos $(2910,3007$ e $3040 \mathrm{kcal} / \mathrm{kg}$ de EM), respectivamente, para as fases inicial, de crescimento e final da criação, e para o testemunha, a ração
\end{abstract}

continha níveis normais de EM e PB, sem enzimas. Os fatores avaliados foram ganho de peso, consumo de ração, conversão alimentar e fator europeu de produção. Pelos resultados, verificou-se manutenção do desempenho zootécnico das aves em razão da aplicação de enzimas, constatado pela não significância desses fatores aos 42 dias de idade e pela melhora na conversão alimentar, redução do consumo de ração e maior fator europeu de produção aos 21 dias de idade. O estudo da interação dos níveis de enzima x proteína mostrou que a adição de $0,5 \mathrm{~g} / \mathrm{kg}$ de enzima na dieta com nível de proteína reduzido resultou em maior ganho de peso das aves. Conclui-se que é viável o uso de enzimas exógenas adicionadas em rações para frangos de corte.

TERMOS PARA INDEXAÇÃO: Enzimas, frangos de corte, milho, farelo de soja.

\section{CORN AND SOYBEAN MEAL BASED DIETS SUPPLEMENTED WITH ENZYMES IN FEED OF BROILER CHICKEN}

\begin{abstract}
The objective of the experiment was verify the effect of the addition of exogen digestive enzymes in corn and soybean meal based diets on performance of broiler chickens. Were used 819 Hubbard chickens in completely randomized design, and $3 \times 2 \times 2+1$ check factorial (enzyme, protein and energy levels and one treatment check) with 3 replications, of the 21 birds by replicate. Enzyme levels were $0.5,1.0$ and $1.5 \mathrm{~g} / \mathrm{kg}$ of diet, energy levels were normal $(3.000 ; 3.100$ and $3.200 \mathrm{kcal} / \mathrm{kg} \mathrm{ME})$ and
\end{abstract}

reduced $(2.910 ; 3.007$ and $3.040 \mathrm{kcal} / \mathrm{kg} \mathrm{ME})$ and the protein levels were normal $(21.18,19.95$ and $19.43 \%$ $\mathrm{CP})$ and reduced $(20.54,19.35$ and $18.46 \% \mathrm{CP})$, respectively, for initial, growing and final phases, check diet had normal level of ME and CP, without enzyme. The body weight gain, ration intake, feed conversion and european factor production were evaluated. The results showed maintenance of the performance due to application of enzymes, that being verified by non significance $(\mathrm{P}>0.05)$ of that factores at

\footnotetext{
1. Professora da Escola Agrotécnica Federal de Crato/CE - Doutoranda - Departamento de Zootecnia da UNIVERSIDADE FEDERAL DE LAVRAS/UFLA - Caixa Postal 37 - 37200-000 - Lavras, MG, delma@navinet.com.br

2. Professores do Departamento de Zootecnia/UFLA.

3. Professor do Departamento de Ciências Exatas/UFLA.

4. Professor da UNIOESTE - PR.

5. Professor da Escola Agrotécnica Federal de Inconfidentes/MG - Doutorando - Departamento de Zootecnia/UFLA.

6. Estudante de Mestrado Departamento de Zootecnia/UFLA.
} 
the 42 days and by improved feed conversion, reduction of the ration intake and higher european factor production at the 21 days of age. The study of the protein and enzyme levels interaction showed that 0.5 $\mathrm{g} / \mathrm{kg}$ of enzyme the addition to the diet with reduced levels of the protein, there was higher weight gain of the birds. It was concluded that is viable the used addition exogen enzymes in ration of broiler chickens.

INDEX THERMS: Enzymes, broiler, corn, soybean meal.

\section{INTRODUÇÃO}

O milho e o farelo de soja são os ingredientes mais utilizados nas dietas das aves e, em razão do consumo elevado, torna as aves competidoras com o homem. O milho, por possuir valor energético alto quando comparado a outros cereais, tem maior importância, justificando, assim, seu uso na alimentação dos animais. Porém, os cereais têm estrutura complexa, composta de grande número de células que se encontram rodeadas por paredes celulares, as quais apreendem amido, proteína e gordura.

Desde a década de 1940, usam-se aditivos nas rações visando a melhorar o desempenho das aves. Enzimas têm sido uma alternativa, pois sua comprovada eficiência em dietas à base de cevada estimulou seu uso em rações contendo outros ingredientes (Chesson, citado por Lima, 1998).

Enzimas são moléculas protéicas com atividade catalisadora que atuam em substratos específicos, como a protease, que age sobre proteína, a amilase, sobre o amido e a xilanase, sobre o xilano. Como proteínas são facilmente biodegradadas, não há restrição de seu uso como aditivo nas dietas.

Por serem específicas nas suas reações catalíticas, os preparados enzimáticos com apenas uma atividade não são suficientes para maximizar sua eficiência como aditivo, fazendo com que a adição de complexos multienzimáticos tornem-se mais eficazes (Finnfeeds,1991).

As enzimas digestivas exógenas atuam basicamente de duas maneiras: rompendo paredes celulares e degradando nutrientes. A maioria das enzimas são substratos dependentes, ou seja, a secreção enzimática é ativada pela presença do substrato; por isso, as aves têm deficiência de enzimas nas primeiras semanas de idade. Mas, existem enzimas que não são secretadas, mesmo na presença de substratos como a celulase, xilanase, pentosanase, $\beta$ - glucanase, fitase, etc, porque o código genético das aves não dispõe da indicação para sua síntese (Penz Jr., 1998).

Realizou-se este experimento com o objetivo de verificar o efeito da adição de um complexo multienzimático em dietas à base de milho e soja sobre o desempenho de frangos de corte, avaliando o ganho de peso, consumo de ração, conversão alimentar e fator europeu de produção aos 21 e 42 dias de idade das aves.

\section{MATERIAL E MÉTODOS}

O experimento foi realizado no Setor de Avicultura do DZO/UFLA, município de Lavras (MG), a uma altitude de 910 metros e temperatura média anual de $19,4^{0} \mathrm{C}$ (Brasil,1992), no período entre 13 de janeiro e 23 de fevereiro de 1999, com duração de 42 dias. Foram utilizados 819 pintos de corte, machos e fêmeas, da linhagem Hubbard, com um dia de idade, vacinados contra doença de Marek e Bouba Aviária. Os animais foram alojados em galpão de alvenaria, com piso de concreto e telhas de cimento-amianto construído na orientação leste-oeste. A instalação possui corredor central, sendo dividida em 40 boxes, 20 de cada lado do galpão, medindo $3,0 \mathrm{~m}^{2}(2,00 \times 1,50)$ cada um.

Ração e água foram fornecidas à vontade, sendo utilizada iluminação constante ( 24 horas). As pesagens foram realizadas semanalmente, sempre pela manhã.

Utilizaram-se 13 tratamentos constituídos de três níveis de enzimas: $0,50,1,00$ e 1,50 g/kg de dieta, em rações à base de milho e farelo de soja, dois níveis de proteína (normal e reduzido) e dois de energia (normal e reduzido), com um tratamento adicional (testemunha, sem enzimas e com níveis normais de proteína e energia). Os níveis reduzidos das dietas foram conseguidos pela diminuição de $3 \%$ nas fases inicial e de crescimento e $5 \%$ na fase final da criação.

As rações usadas foram de três tipos (Rostagno, Barbarino e Barboza, 1996), segundo a fase de criação (Tabela 1), sendo fareladas, à base de milho e farelo de soja. A ração inicial foi utilizada até a terceira semana, a de crescimento, da terceira até a quinta, e a ração final na última semana de idade das aves.

O complexo multienzimático utilizado é composto pelas enzimas $\alpha$ - amilase (2000U/g), protease $(6000 \mathrm{U} / \mathrm{g})$ e xilanase $(800 \mathrm{U} / \mathrm{g})$, recomendado para a espécie avícola em dietas de baixa viscosidade como o milho e o farelo de soja.

O desempenho zootécnico foi avaliado pelo ganho de peso, consumo de ração, conversão alimentar e fator europeu de produção. 
As aves de cada parcela foram pesadas semanalmente para avaliações de ganhos de peso semanais, sendo considerado para análise estatística o ganho de peso diário das aves. A balança usada apresentava capacidade para $150 \mathrm{~kg}$ e precisão de $100 \mathrm{~g}$.

A avaliação do consumo de ração foi realizada a cada 7 dias, retirando-se a sobra dos comedouros e subtraindo-se do total de ração fornecida. Foi obtido o consumo médio ave/dia usando balança digital com capacidade para 7,5 kg e precisão de 5 gramas.

A conversão alimentar foi obtida dividindo-se o consumo médio de ração pelo ganho de peso médio dos frangos.

O cálculo do fator europeu de produção ou índice europeu de eficiência produtiva ocorreu em cada parcela experimental aos 21 e 42 dias de idade, pela fórmula citada por Cotta (1997), expressa por:

F.P. $=\mathrm{Gmd} \times \mathrm{Vb} \times \mathrm{E} \mathrm{A} \times 100$

Sendo:

Gmd $=$ ganho médio diário $=\frac{\text { peso vivo }(\mathrm{kg})}{\text { idade em dias }}$

$\mathrm{Vb}=$ viabilidade $(\%)=100-(\%)$ mortalidade

$\mathrm{EA}=$ eficiência alimentar $=\frac{1}{\text { conversão alimentar }}$

TABELA 1 - Composição das dietas experimentais.

\begin{tabular}{|c|c|c|c|c|c|c|c|c|c|c|c|c|c|}
\hline \multirow{2}{*}{ Ingredientes } & \multirow{2}{*}{ Unid. } & \multicolumn{4}{|c|}{$\begin{array}{r}\text { Fase inicial } \\
\text { (1 a } 21 \text { dias) }\end{array}$} & \multicolumn{4}{|c|}{$\begin{array}{l}\text { Fase de crescimento } \\
\quad(22 \text { a } 35 \text { dias })\end{array}$} & \multicolumn{4}{|c|}{$\begin{array}{c}\text { Fase final } \\
\text { (36 a } 42 \text { dias) }\end{array}$} \\
\hline & & $\begin{array}{c}\text { Ração } \\
1\end{array}$ & $\begin{array}{l}\text { Ração } \\
2\end{array}$ & $\begin{array}{c}\text { Ração } \\
\mathbf{3}\end{array}$ & $\begin{array}{c}\text { Ração } \\
\mathbf{4}\end{array}$ & $\begin{array}{c}\text { Ração } \\
1\end{array}$ & $\begin{array}{l}\text { Ração } \\
2\end{array}$ & $\begin{array}{c}\text { Raçãa } \\
\mathbf{3}\end{array}$ & $\begin{array}{c}\text { Ração } \\
\mathbf{4}\end{array}$ & $\begin{array}{c}\text { Ração } \\
1\end{array}$ & $\begin{array}{l}\text { Raçãa } \\
2\end{array}$ & $\begin{array}{c}\text { Ração } \\
\mathbf{3}\end{array}$ & $\underset{\mathbf{4}}{\text { Ração }}$ \\
\hline 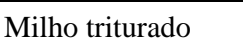 & $\mathrm{K}$ & 55,585 & 57,665 & 57,685 & 59,765 & 59,245 & 61,205 & 61,425 & 63,375 & 58,91 & 62,07 & 62,65 & 65,82 \\
\hline Farelo c & $\mathrm{Kg}$ & 36,98 & 35,22 & 36,64 & 34,87 & 33,52 & 31,87 & 33,16 & 31,51 & 32,48 & 29,80 & 31,86 & 29,18 \\
\hline Fosfato bicálcico & $\mathrm{Kg}$ & 1,95 & 1,96 & 1,94 & 1,95 & 1,68 & 1,68 & 1,67 & 1,68 & 1,52 & 1,54 & 1,51 & 1,53 \\
\hline Óleo vegetal & $\mathrm{Kg}$ & 3,44 & 3,09 & 1,69 & 1,34 & 3,53 & 3,20 & 1,72 & ,39 & 5,07 & 4,54 & 1,96 & 1,42 \\
\hline Calcário calcítico & $\mathrm{kg}$ & & & & & & & & & & 1,17 & 1,17 &, 17 \\
\hline Cloreto de sódio & $\mathrm{kg}$ & 0,39 & 0,39 & 0,39 & 0,39 & 0,40 & 0,40 & 0,40 & 0,40 & 0,40 & 0,40 & 0,40 & 0,40 \\
\hline DL-metionina & $\mathrm{kg}$ & 0,19 & 0,21 & 0,19 & 0,21 & 0,14 & 0,16 & 0,14 & 0,16 & 0,12 & 0,14 & 0,11 & 0,14 \\
\hline Colina & $\mathrm{kg}$ & 0,07 & 0,07 & 0,07 & 0,07 & 0,06 & 0,06 & 0,06 & 0,06 & 0,06 & 0,06 & 0,06 & 0,06 \\
\hline Premix 1 & $\mathrm{~kg}$ & 0,05 & 0,05 & 0,05 & 0,05 & 0,05 & 0,05 & 0,05 & 0,05 & 0,05 & 0,05 & 0,05 & 0,05 \\
\hline Premix vit & $\mathrm{kg}$ & 0,03 & 0,03 & 0,03 & 0,03 & 0,03 & 0,03 & 0,03 & 0,03 & 0,03 & 0,03 & 0,03 & 0,03 \\
\hline Surmax 100 & $\mathrm{~kg}$ & 0,005 & 0,005 & 0,005 & 0,005 & 0,005 & 0,005 & 0,005 & 0,005 & - & - & - & - \\
\hline Coxistac & $\mathrm{kg}$ & 0,05 & 0,05 & 0,05 & 0,05 & 0,05 & 0,05 & 0,05 & 0,05 & 0,05 & 0,05 & 0,05 & 0,05 \\
\hline Inerte & $\mathrm{kg}$ & 0,15 & 0,15 & 0,15 & 0,15 & 0,15 & 0,15 & 0,15 & 0,15 & 0,15 & 0,15 & 0,15 & 0,15 \\
\hline Total & kg & & 100,00 & 100,00 & 100,00 & 100,00 & 100,00 & 100,00 & 100,00 & 100,00 & 100,00 & 100,00 & 100,00 \\
\hline \multicolumn{14}{|l|}{ Composição } \\
\hline E.M & $\mathrm{kcal} / \mathrm{kg}$ & 3.000 & 3.000 & & 2910 & 3.100 & 3.100 & 3.007 & & & 3.200 & 3.040 & 3.040 \\
\hline P.B & $\%$ & 21,18 & 20,54 & 21,18 & 20,54 & 19,95 & 19,35 & 19,95 & 19,35 & 19,43 & 18,46 & 19,43 & 18,46 \\
\hline $\mathrm{Ca}$ & $\%$ & 1,00 & 1,00 & & 1,00 & 0,94 & 0,94 & 0,94 & 0,94 & 0,91 & 0,91 & 0,91 & 0,91 \\
\hline P. dispo & $\%$ & 0,45 & 0,45 & 0,45 & 0,45 & 0,40 & 0,40 & 0,40 & 0,40 & 0,37 & 0,37 & 0,37 & 0,37 \\
\hline Lisina & $\%$ & 1,19 & 1,14 & 1,18 & 1,14 & 1,10 & 1,06 & 1,09 & 1,05 & 1,07 & 1,00 & 1,06 & 0,99 \\
\hline $\mathrm{Na}$ & $\%$ & 0,20 & 0,20 & 0,20 & 0,20 & 0,20 & 0,20 & 0,20 & 0,20 & 0,20 & 0,20 & 0,20 & 0,20 \\
\hline Metionina & $\%$ & 0,53 & 0,54 & 0,53 & 0,53 & 0,46 & 0,47 & 0,46 & 0,47 & 0,43 & 0,44 & 0,43 & 0,44 \\
\hline Met. + Cistina & $\%$ & 0,88 & 0,88 & 0,88 & 0,88 & 0,80 & 0,80 & 0,80 & 0,80 & 0,76 & 0,76 & 0,76 & 0,76 \\
\hline
\end{tabular}


Conversão alimentar $=\frac{\text { consumo de ração }}{\text { peso do animal }}$

O delineamento estatístico utilizado foi um DIC em esquema fatorial $3 \times 2 \times 2+1$ (níveis de enzima, proteína, energia e um tratamento testemunha), com 3 repetições e 21 aves por parcela. As análises estatísticas foram realizadas por meio do software SISVAR (Sistema de Análise de Variância de Dados Balanceados) desenvolvido por Ferreira (1998). As médias do tratamento adicional $\mathrm{x}$ fatorial foram comparadas pelo teste $\mathrm{F}$, sendo feito desdobramento quando significativo. As médias dos níveis de enzimas foram comparadas pelo teste de Tukey $(\mathrm{P}=0,05)$.

\section{RESULTADOS E DISCUSSÕES}

Os valores de ganho de peso diário médio $(\mathrm{g})$ das aves aos 21 dias de idade que receberam dietas contendo diferentes níveis de enzimas encontram-se na Tabela 2. A análise de variância não demonstrou diferença $(\mathrm{P}>0,05)$ entre as médias do fatorial e do adicional, inferindo-se que o fatorial teve efeito semelhante ao adicional. Houve interação significativa $(\mathrm{P}<0,05)$ entre os fatores avaliados. $\mathrm{O}$ estudo da interação enzima x proteína mostrou que quando se utilizou nível reduzido de proteína, a adição de 0,5 e 1,0 g/ $\mathrm{kg}$ de enzimas apresentou maiores ganhos de pesos, evidenciando que dietas com menor densidade nutricional apresentam melhor resposta de desempenho, decorrente da ação enzimática, degradando e liberando nutrientes contidos nos ingredientes das rações. Zanella (1999), ao avaliar o mesmo complexo enzimático em rações à base de milho e farelo de soja com níveis reduzidos de nutrientes, não observou diferenças $(\mathrm{P}>0,05)$ no ganho de peso dessas aves com as alimentadas com níveis normais de nutrientes, aos 21 dias de idade.

O estudo dos níveis de proteína dentro de cada nível de enzima revelou que só houve diferença quando se adicionou $1,5 \mathrm{~g} / \mathrm{kg}$ de enzima na dieta. Nesse caso, o maior nível de proteína promoveu maior ganho de peso, demonstrando que esse nível atendeu às necessidades nutritivas das aves. Essas observações não estão de acordo com as descrições de CHARLTON (1996), de que efeitos benéficos pelo uso de enzimas são limitados quando essas são utilizadas acima das necessidades das aves.

Na Tabela 3 encontram-se os valores de consumo de ração diário médio $(\mathrm{g})$ das aves aos 21 dias de idade que receberam dietas contendo diferentes níveis de enzimas. A análise de variância demonstrou diferença $(\mathrm{P}<0,05)$ entre as médias do fatorial e do adicional, mostrando que o fatorial apresentou menor consumo de ração que o tratamento adicional, evidenciando a capacidade das enzimas em proporcionarem melhor aproveitamento da proteína e da energia, uma vez que o fatorial continha níveis inferiores desses nutrientes, com o menor consumo atendendo às exigências nutritivas das aves. Aos 21 dias de idade, Zanella (1999), ao avaliar o mesmo complexo enzimático em rações à base de milho e farelo de soja com níveis reduzidos de nutrientes, não observou diferença $(\mathrm{P}>0,05)$ no consumo de ração dessas aves com as alimentadas com níveis normais de nutrientes.

TABELA 2 - Médias de ganho de peso diário (g) aos 21 dias (*).

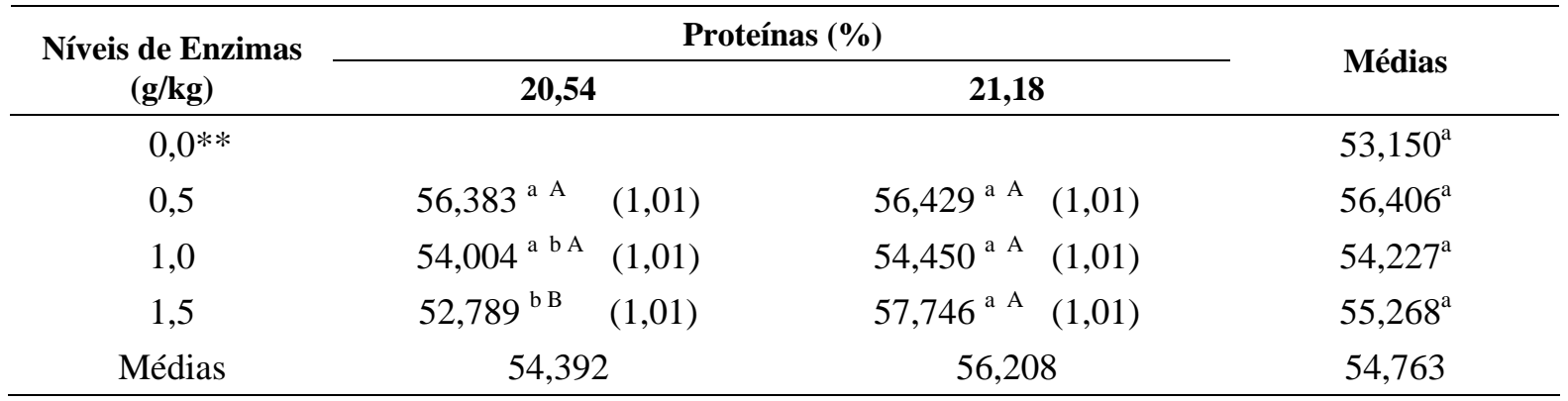

*Dentro de cada coluna, médias seguidas de letras minúsculas distintas diferem significativamente $(P<0,05)$ pelo teste de Tukey.

*Dentro de cada linha, médias seguidas de letras maiúsculas distintas diferem significativamente $(\mathbf{P}<0,05)$ pelo teste $\mathbf{F}$.

** Adicional

Ciênc. agrotec., Lavras. V.27, n.1, p.199-205, jan./fev., 2003 
Houve interação significativa $(\mathrm{P}<0,05)$ entre os fatores avaliados. $\mathrm{O}$ estudo da interação enzimas $\mathrm{x}$ proteínas mostrou haver diferença no consumo de ração dos frangos quando se usou maior proteína. Nesse caso, a adição de $1,0 \mathrm{~g}$ de enzimas $/ \mathrm{kg}$ de dieta apresentou menor consumo, demonstrando que esse nível atendeu às exigências em nutrientes das aves. $\mathrm{O}$ efeito dos níveis de proteínas em cada nível de enzima revelou que não houve diferença quando a adição foi $1,5 \mathrm{~g} / \mathrm{kg}$ de enzima na dieta. Com adição de $0,5 \mathrm{~g} / \mathrm{kg}$ e $1,0 \mathrm{~g} / \mathrm{kg}$, a maior proteína apresentou menor consumo.

Apresentam-se na Tabela 4 os valores das médias de conversão alimentar e do fator europeu de produção aos 21 dias de idade das aves que receberam dietas contendo diferentes níveis de enzimas. A análise de variância demonstrou que as médias obtidas no fatorial foram similares entre si $(\mathrm{P}>0,05)$, porém diferiram do tratamento adicional $(\mathrm{P}<0,05)$. O resultado de melhor conversão alimentar e de maior fator europeu de produção apresentado pelo fatorial é atribuído ao maior ganho de peso e menor consumo de ração das aves. Isso demonstra que as enzimas foram eficientes em proporcionarem melhor aproveitamento dos componentes das dietas, uma vez que elas continham níveis inferiores de proteína e de energia.

As observações de melhor conversão alimentar são semelhantes às verificadas por Zanella (1999), usando níveis normais de nutrientes em aves tratadas com complexo multienzimático aos 21 dias de idade. Em outro experimento utilizando níveis reduzidos de nutrientes, Zanella (1999), ao avaliar o mesmo complexo enzimático em rações à base de milho e farelo de soja, não observou diferença $(\mathrm{P}>0,05)$ na conversão alimentar dessas aves com as alimentadas com níveis normais de nutrientes. Na literatura consultada não foram observados resultados relacionados ao fator europeu de produção e aplicação de enzimas nessa fase de produção.

TABELA 3 - Consumo de ração diário médio (g) aos 21 dias (*).

\begin{tabular}{|c|c|c|c|}
\hline \multirow{2}{*}{$\begin{array}{l}\text { Níveis de Enzimas } \\
(\mathrm{g} / \mathrm{kg})\end{array}$} & \multicolumn{2}{|c|}{ Proteínas (\%) } & \multirow{2}{*}{ Médias } \\
\hline & 20,54 & 21,18 & \\
\hline $0,0^{* * *}$ & & & $91,502^{b}$ \\
\hline 0,5 & $95,477^{\text {a } \mathrm{B}} \quad(1,60)$ & $88,922^{\text {b A }} \quad(1,60)$ & 92,200 \\
\hline 1,0 & $90,610^{\text {a } ~}$ & $81,869^{\text {a } \mathrm{A}}(1,60)$ & 86,240 \\
\hline 1,5 & $90,091^{\text {a } \mathrm{A}} \quad(1,60)$ & $90,985^{\text {b A }}(1,60)$ & 90,538 \\
\hline Médias & 92,059 & 87,259 & $90,120^{\circ}$ \\
\hline CV\% & 4,23 & & \\
\hline
\end{tabular}

*Dentro de cada coluna, médias seguidas de letras minúsculas distintas diferem significativamente $(\mathbf{P}<0,05)$ pelo teste de Tukey.

*Dentro de cada linha, médias seguidas de letras maiúsculas distintas diferem significativamente $(\mathbf{P}<0,05)$ pelo teste $\mathrm{F}$.

**Adicional

TABELA 4 - Médias de conversão alimentar (CA) e fator de produção (FEP) aos 21 dias (*).

\begin{tabular}{ccccc}
\hline Níveis de Enzimas (g/kg) & \multicolumn{2}{c}{ CA } & \multicolumn{2}{c}{ FEP } \\
\hline $0,0^{* *}$ & $1,722^{\mathrm{b}}$ & $(0,03)$ & $216^{\mathrm{b}}$ & $(10,56)$ \\
0,5 & $1,636^{\mathrm{a}}$ & $(0,03)$ & $343^{\mathrm{a}}$ & $(10,56)$ \\
1,0 & $1,593^{\mathrm{a}}$ & $(0,03)$ & $337^{\mathrm{a}}$ & $(10,56)$ \\
1,5 & $1,644^{\mathrm{a}}$ & $(0,03)$ & $336^{\mathrm{a}}$ & $(10,56)$ \\
Médias & 1,649 & & 308 & \\
\hline
\end{tabular}

*Dentro de cada coluna, médias seguidas de mesma letra não diferem significativamente $(\mathbf{P}>0,05)$ pelo teste $\mathbf{F}$. ** Adicional 
Na Tabela 5 encontram-se os valores de ganho de peso diário médio $(\mathrm{g})$ e de consumo de ração diário médio ( $\mathrm{g}$ ) das aves aos 42 dias de idade que receberam dietas contendo diferentes níveis de enzimas. A análise de variância não demonstrou diferença $(\mathrm{P}>0,05)$ entre as médias do fatorial e do adicional, significando que o fatorial teve efeito semelhante ao tratamento adicional. Isso demonstra a eficiência das enzimas em degradar e liberar nutrientes contidos em dietas com menor densidade nutricional, proporcionando desempenho semelhante às aves alimentadas com dietas constituídas de níveis nutricionais normais.

As observações de ganho de peso são semelhantes às verificadas por Costa (1996), mas diferem das encontradas por Mendes et al.,(1981), SotoSalanova (1996), Schang (1996) e Figueiredo et al. (1998), que constataram maior ganho de peso em aves tratadas com complexo multienzimático aos 42 dias de idade.

As observações encontradas no consumo de ração são semelhantes às verificadas por Costa (1996) e Figueiredo et al.(1998), mas diferem das encontrados por Soto-Salanova (1996), que observou menor consumo em frangos alimentados com adição de enzimas aos 42 dias de idade.
Encontram-se na Tabela 6 os valores das médias de conversão alimentar (CA) e do fator europeu de produção (FEP) das aves aos 42 dias de idade que receberam dietas contendo diferentes níveis de enzimas. A análise de variância não demonstrou diferença $(\mathrm{P}>0,05)$ entre as médias do fatorial e do adicional, inferindo-se que o fatorial teve efeito semelhante ao tratamento adicional, evidenciando a capacidade das enzimas em proporcionarem melhor aproveitamento dos componentes das dietas de menor densidade nutricional, uma vez que elas continham níveis inferiores de proteína e energia.

Os resultados observados na conversão alimentar não estão de acordo com os verificados por SotoSalanova, Schang (1996) e Figueiredo (1998), que observaram diferenças $(\mathrm{P}<0,05)$ na conversão pela aplicação de enzimas exógenas nessa fase de produção.

As observações de fator europeu de produção são semelhantes às verificadas por Zanella (1999), usando níveis reduzidos de nutrientes em aves tratadas com complexo enzimático aos 42 dias. Em outro experimento, utilizando níveis normais de nutrientes, Zanella (1999), ao avaliar o mesmo complexo em rações à base de milho e farelo de soja, observou diferenças $(\mathrm{P}<0,05)$ no fator europeu de produção em conseqüência da aplicação de enzimas.

TABELA 5 - Médias de ganho de peso (GP) diário (g) e consumo de ração diário médio (CR) aos 42 dias (*).

\begin{tabular}{|c|c|c|}
\hline Níveis de Enzimas (g/kg) & GP & CR \\
\hline $0,0 * *$ & $74,860^{\mathrm{a}} \quad(2,42)$ & $172,781^{\mathrm{a}} \quad(2,40)$ \\
\hline 0,5 & $73,192^{\mathrm{a}} \quad(2,42)$ & $175,249^{\mathrm{a}} \quad(2,40)$ \\
\hline 1,0 & $70,889^{\mathrm{a}} \quad(2,42)$ & $179,623^{\mathrm{a}} \quad(2,40)$ \\
\hline 1,5 & $75,367^{\mathrm{a}} \quad(2,42)$ & $181,397^{\mathrm{a}} \quad(2,40)$ \\
\hline Médias & 73,149 & 177,263 \\
\hline
\end{tabular}

\section{*Dentro de cada coluna, médias seguidas de mesma letra não diferem significativamente $(\mathbf{P}>0,05)$ pelo teste $\mathbf{F}$.} ** Adicional

TABELA 6 - Médias de conversão alimentar (CA) e fator de produção (FEP) aos 42 dias (*).

\begin{tabular}{cccc}
\hline Níveis de Enzimas $(\mathbf{g} / \mathbf{k g})$ & \multicolumn{2}{c}{ CA } & \multicolumn{2}{c}{ FEP } \\
\hline $0,0^{* *}$ & $2,338^{\mathrm{a}}(0,09)$ & $312^{\mathrm{a}}$ & $(17,44)$ \\
0,5 & $2,409^{\mathrm{a}}$ & $(0,09)$ & $301^{\mathrm{a}}(17,44)$ \\
1,0 & $2,593^{\mathrm{a}}(0,09)$ & $274^{\mathrm{a}}(17,44)$ \\
1,5 & $2,423^{\mathrm{a}}(0,09)$ & $302^{\mathrm{a}}(17,44)$ \\
Médias & 2,441 & & 297,3 \\
\hline
\end{tabular}

*Dentro de cada coluna, médias seguidas de mesma letra não diferem significativamente $(\mathbf{P}>0,05)$ pelo teste $\mathbf{F}$. ** Adicional

Ciênc. agrotec., Lavras. V.27, n.1, p.199-205, jan./fev., 2003 


\section{CONCLUSÕES}

A utilização de enzimas digestivas exógenas em dietas à base de milho e soja, com níveis reduzidos de proteína e energia, melhorou o desempenho das aves aos 21 dias de idade. Aos 42 dias, manteve o mesmo desempenho zootécnico observado nas aves alimentadas com dietas que apresentavam de níveis nutricionais normais. Com esses resultados, demonstra-se a possibilidade de formular rações constituídas de níveis mais baixos de nutrientes com adição de enzimas, podendo concluir que, nutricionalmente, é viável a suplementação de enzimas em rações à base de milho e farelo de soja para frangos de corte; entretanto, a sua execução depende da análise custo/benefício.

\section{REFERÊNCIAS BIBLIOGRÁFICAS}

BEDFORD, M. R. Efeito del uso de enzimas digestivas en la alimentacióne de aves. Avicultura Profesional, Georgia, v.14, n.4, p.24-29, 1996.

BRASIL. Ministério da Agricultura. Normas climatológicas. 1961/1990, Brasília,1992

CANTOR, A. Enzimas usadas na Europa, Estados Unidos e Ásia. Possibilidades para uso no Brasil. In: RONDA LATINO AMERICANA DE BIOTECNOLOGIA 5. Curitiba, 1995 Anais... Curitiba: ALLTECH, 1995, p.31-32.

CHARLTON, P. Expanding enzyme application: Higher amino acid and energy values for vegetable proteins. In: BIOTECNOLOGY IN THE FEED INDUSTRY, 12. 1996. Proccedings. Nicholasville: Alltech Techinical Publications, 1996. p. 317-326.

COSTA, F. G. P. Efeito de adição de enzimas nas rações de frango de corte. Areia - PB: CCA/UFPB 1996, 56 p. Dissertação (Mestrado em Produção Animal) Universidade Federal da Paraíba.

FERREIRA, D. F. Sistema de análise de Variância de Dados Balanceados. Pacote computacional. DEXUFLA. Lavras. 1998.
FIGUEIREDO, A. N., ZANELLA, I., SAKOMURA, N. K., LONGO, F. A., PACK, M., JUNQUEIRA, O. M. Efeito da adição de enzimas em dietas à base de milho e tipos de soja sobre o desempenho de frangos de corte. In: CONFERÊNCIA APINCO DE CIÊNCIAS E TECNOLOGIAS AVÍCOLAS, 1998.Campinas, Anais..., Campinas: Facta, 1998, p.36.

FINNFEEDS INTERNATIONAL. Enzymes in animal nutrition. In Feed Enzymes. Technical Support Manual. England,, 1991, p.11-16.

LIMA, A. C. F. de., PIZAURO Jr, J. M., RAMBOUSEK, M. J., HARNICH, F. A .R., MACARI, M. Avaliação do desempenho de frangos de corte alimentados com suplementação enzimática ou probiótica. In: CONFERÊNCIA APINCO DE CIÊNCIAS E TECNOLOGIAS AVÍCOLAS,1998. Campinas, Anais..., Campinas: Facta, 1998, p.05.

MENDES, A. A., PATRÍcio, I. S., PEZZATO, A. C. Efeito da adição de enzimas em rações para frangos de corte - Amilase, protease, celulase. São Paulo: UNESP, 1981, p.10.

PENZ Jr, A.M. Enzimas em rações de aves e suínos. In: REUNIÃO ANUAL DA SOCIEDADE BRASILEIRA DE ZOOTECNIA, 35., 1998, Botucatu, SP. Anais... Botucatu, SP:SBZ, 1998. p. 165-178.

ROSTAGNO, H. S., BARBARINO JR, P., BARBOZA, W. A. Exigências nutricionais das aves determinadas no Brasil. In: SIMPÓSIO INTERNACIONAL SOBRE EXIGÊNCIAS NUTRICIONAIS DE AVES E SUÍNOS. Viçosa- UFV. 1996 p.361-388.

SCHANG, M. J. O uso da enzima vegpro em dietas para frangos em crescimento. In: RONDA LATINO AMERICANA DE BIOTECNOLOGIA 6. Curitiba, 1996. Anais... Curitiba: ALLTECH, 1996, p.71-77.

SOTO-SALANOVA, M. The use of enzymes to improve the nutritional value of corn-soy diets for poultry and swine. In: SIMPÓSIO LATINO AMERICANO DE NUTRIÇÃO DE SUÍNOS E AVES, 1996. Campinas, p.1-13. 